\section{A Giant Fibrovascular Polyp Regurgitating Outside the Mouth upon Coughing}

\section{Abstract}

Fibrovascular polyp (FVP) is a benign tumor of the upper esophagus which can remain silent for a long period of time until it becomes large enough to cause symptoms such as: vomiting and air way obstruction. In the following article, we present a 54 years old female complaining from (FVP) regurgitating from her mouth upon coughing. Upon surgery, the findings was consistent with fibrotic tissue isolating areas of adipose tissue.

Keywords: Fibrovascular polyp; Upper esophagus; Mouth; Respiratory compromise

Received: December 11, 2017; Accepted: December 26, 2017; Published: December 29, 2017

\section{Introduction}

Giant Fibrovascular Polyp (FVP) of esophagus is a rare mass arising in the proximal esophagus and can cause airways obstruction due to mechanical pressure. They are accounting for approximately $1 \%$ of esophageal benign tumors [1]. Usually these polyps arise from the cervical esophagus, inferiorly to the cricopharyngeal muscle, and this area has also been termed as the LaimerHaeckermann triangle (also known as the Laimer's triangle) [2]. that is why, they tend to protrude into the mouth giving the shape of a fleshy mass. These lesions do not give symptoms until they grow in size where they cause dysphagia, vomiting, hoarseness, chronic gastrointestinal bleeding, respiratory symptoms and weight loss [3]. They can also regurgitate into the mouth causing asphyxiation in some described cases [4].

Commonly used diagnostic investigation includes barium doublecontrast examination of the esophagus, which shows a sausageshaped mass with multiple filling defects. Endoscopy visualizes an intraluminal mobile mass covered with normal mucosa, emerging from the upper esophagus. Endoscopic ultrasonography may be used providing information on a diameter of a polyp, as well as its vascularity at insertion point. At $\mathrm{CT}$, fibrovascular polyps can manifest different degrees of attenuation values according to the proportions of fibrous and adipose tissues.

The mainstay of treatment once diagnosis is reached is resection, which is necessary in view of the potential risk of respiratory compromise, bleeding, and the debilitating symptoms [5].

The choice between surgery or endoscopic resection, depends on the size, the location of the stalk's base, its mobility, and the

\section{Ahmad Mustafa ${ }^{1}$, Raeda al Khani ${ }^{2}$ and Maher Salamoon ${ }^{3 *}$}

1 Deapartment of Head and Neck, Al Mwassa University Hospital, Damascus, Syria

2 Deapartment of Pathology, Al Mwassa Hospital, Damascus, Syria

3 Department of Medical Oncology, Al Bairouni University Cancer Center, Damascus, Syria

*Corresponding author: Maher Salamoon Maher.salamoon@gmail.com

Department of Medical Oncology, Al Bairouni University Cancer Center, Damascus, Syria.

Tel: +963933771086

Citation: Mustafa A, Khani RA, Salamoon M (2017) A Giant Fibrovascular Polyp Regurgitating Outside the Mouth upon Coughing. J Clin Epigenet. Vol.3 No.4:48

vessels that nourish it. The FP less than $2 \mathrm{~cm}$ can be removed by endoscopic resection. But those larger than $5 \mathrm{~cm}$ usually require open surgical resection, because of the thick vascularized pedicle. In most cases, the left-sided cervical is the preferred approach. If the diagnosis is not clear or the lesion cannot be completely removed through the simple esophagostomy, esophageal resection may be necessary.

In conclusion, giant fibrovascular polyps are uncommon benign neoplasms of the esophagus and its recurrences are more uncommon. Resection is recommended in view of potential deadly complications. Endoscopic resections, open surgery via trans-cervical, trans-thoracic, or trans-abdominal approaches have been used. Investigations should aim to identify the pedicle's origin and the bulk of the polyp before operation, to aid in the planning of the surgical approach $[6,7]$.

We present a 54 years old female complaining from progressive dysphagia and episodes of dyspnea over 3 years with a $25 \mathrm{~cm}$ length mass protruding out of the mouth upon coughing. The 
polyp was resected by endoscopy using laser therapy. Pathologic findings showed an admixture of adipose and fibrotic tissue with reactive squamous epithelial lining leading to the diagnosis of fibrovascular polyp. (FVP) though it is a rare entity in esophagus and easy to diagnose in some cases, however, it can cause serious morbidity.

Our patient has signed an informed consent for both being operated and for using images for scientific and educational purposes.

\section{Report of Case}

A 54 years old Syrian lady was seen at Al Mwassa university hospital (department of head and neck diseases) for a progressive dysphagia since 3 years and several daily episodes of dyspnea. The patient mentioned a regurgitation of a fleshy, sausage-like mass out of the mouth upon coughing where she was obliged to swallow it again with hand support. Esophagoscopy revealed a mobile elongated polypoid mass extending from the upper esophageal sphincter till the cardioesophageal junction.

The surgeon decided to excise the mass and after stretching the polyp outside the mouth, the mass ablation was performed by laser therapy (Figure 1). The mass was completely removed and the patient started to swallow liquids the second day after surgery and solids 10 days later.

\section{Pathologic Finding}

A sausage-like mass measuring $25 \mathrm{~cm}$ with a glistening and tanpink surface. On longitudinal cut, an admixture of both adipose and fibrotic tissue was seen with some degree of necrosis (Figure 2). The dense connective tissue showed also dilated blood vessels. So, the former findings are compatible with fibro vascular polype.

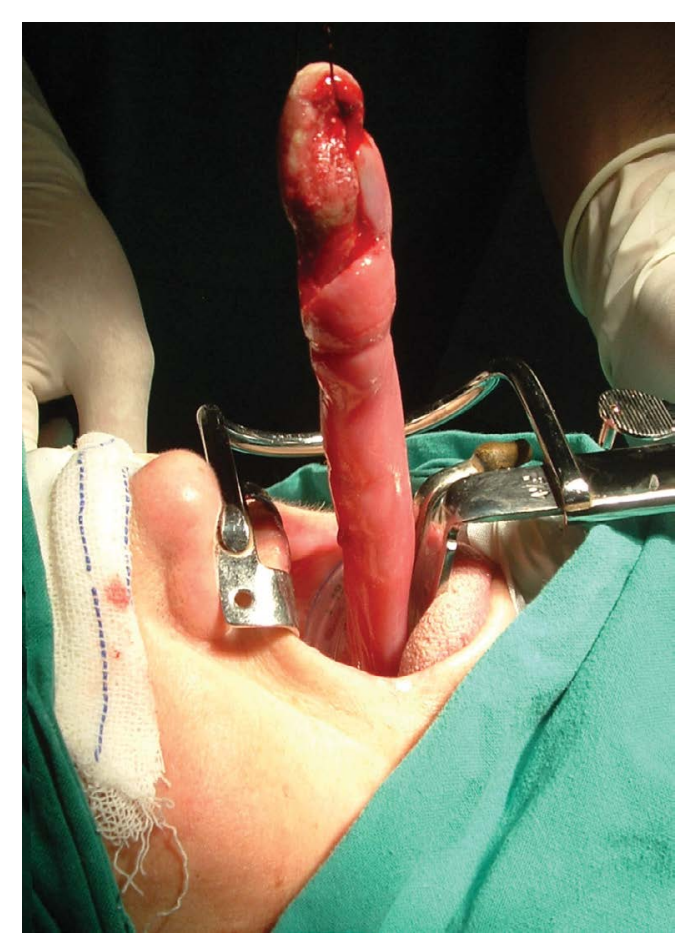

Figure 1 Polype stretching out of the mouth before surgery.

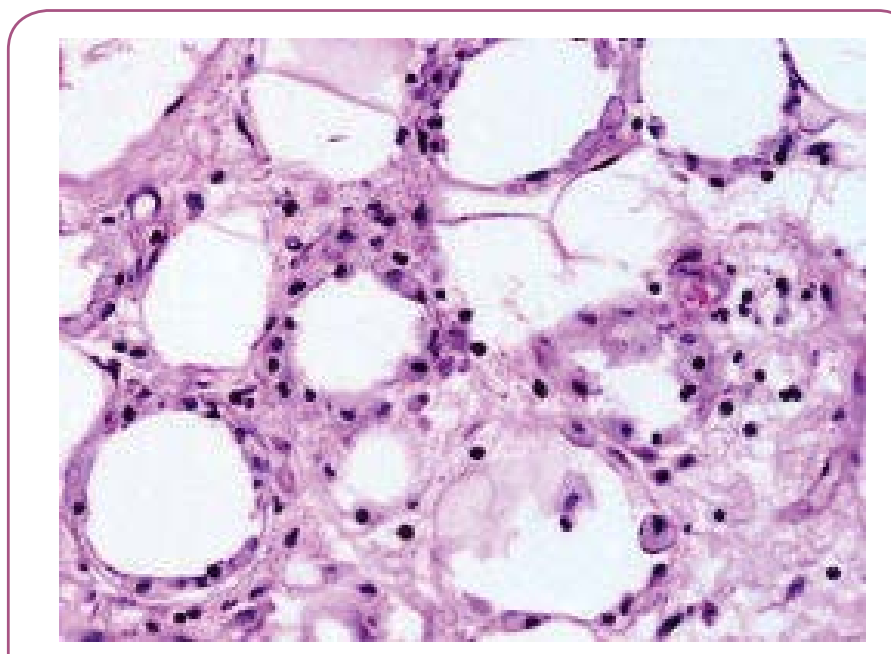

Figure 2 Focal fat necrosis (hematoxylin-eosin) x 200 .

\section{Technical Approach}

Tracheal intubation previous to upper endoscopy was donee; the mass measured $28 \times 2,5 \mathrm{~cm}$ and was held from the distal portion and pulled into the mouth giving a clear image of the implantation base at the Killian's triangle. Once the distal portion of the tumor was fixed into the mouth and the base trapped by means of Kantrowitz forceps, the video assisted endoscopic surgery. The tumor was pulled by means of Magill forceps, and the base of the tumor was electrocoagulated with the hook right above the Kantrowitz forceps the thing that enabled us controlling any possible hemorrhage.

In the second day after surgery, the patient was able to eat soft meals and she was discharged after 72 hours of surgery.

\section{Discussion}

FVP is a benign lesion arising from the esophagus and rarely from the oropharynx. diagnosed only when it starts to enlarge in size causing esophageal obstruction and mechanical pressure on bronchus causing difficulties in swallowing and dyspnea respectively [7]. Esophagogram can be made by barium revealing distended esophagus with filling defect [8]. In majority of cases, diagnosis is made by watching a regurgitating mass to the oral cavity. Since 1969, only 16 cases of FVP have been registered in the United states. FVP occurs at any age but it peaks in middle age, however, some cases are seen in children $[9,10]$. Levine et al. [7] reported a series of 16 patients presented with dysphagia in $87 \%$ and dyspnea in $25 \%$ and $12 \%$ with regurgitation. Not clearly reported, asphyxiation could happen due to larynx obstruction by the mass. Due to the polyp length and the upper localization in the esophagus, the patient in our case presented by regurgitation upon coughing which is not a usual presentation, but even though, the patient coped with during 4 years period.

The mean duration of symptoms ranged between 10 and 17 months as Levine et al. reported, while some patients presented emergently [11]. Reported cases were between 11 and $25 \mathrm{~cm}$ in 
length and polyp in our case reached $25 \mathrm{~cm}$ in length forming one of the top length reported fibrovascular polyp.

Finally, knowing the exact localization of the polyp is crucial for

\section{References}

1 Sargent RL, Hood IC (2006) Asphyxiation caused by giant fibrovascular polyp of the esophagus. Arch Pathol Lab Med 130: 725-727.

2 McLean JN, DelGaudio JM (2007) Endoscopic resection of a giant esophageal polyp: case report and review of the literature. Am J Otolaryngol 28: 115-117.

3 Pajor A, Maciaszczyk K, Wagrowska-Danilewicz M, Pazurek M, Murlewska A, et al. (2013) Rare case of giant fibrovascular polyp of the esophagus] Otolaryngol Pol 67: 176-179.

4 Carrick C, Collins KA, Lee CJ, Prahlow JA, Barnard JJ (2005) Sudden death due to asphyxia by esophageal polyp: two case reports and review of asphyxial deaths. Am J Forensic Med Pathol 26: 275-281.

5 Park JS, Bang BW, Shin J, Kwon KS, Kim HG, Shin YW, et al. A Case of Esophageal Fibrovascular Polyp That Induced Asphyxia during Sleep. Clin Endosc 47: 101-103.

6 H, Kim JS, Shim YM (2006) Giant fibrovascular polyp of the surgery planning and this could be made by CT-Scan or MRI as well as esophagoscopy. Most surgeries used opening through the neck, however, our case was excised through endoscopic approach from the mouth.

hypopharynx: surgical treatment with the biappoach. J Korean Med Sci 21:749-751.

7 Levine MS, Buck JL, Pantongrag-Brown L, Buetow PC, Hallman JR, et al. (1996) Fibrovascular polyps of the esophagus: clinical, radiographic, and pathologic findings in 16 patients. AJR Am J Roentgenol 166: 781-787.

8 Drenth J, Wobbes T, Bonenkamp JJ, Nagengast FM (2002) Recurrent esophageal fibrovascular polyps: case history and review of the literature. Dig Dis Sci 47: 2598-2604.

9 Paik HC, Han JW, Jung EK, Bae KM, Lee YH (2001) Fibrovascular polyp of the esophagus in an infant. Yonsei Med J 42: 264-266.

10 Seshul MJ, Wiatrak BJ, Galliani CA (1998) Pharyngeal fibrovascular polyp in a child. Ann Otol Rhinol Laryngol 107: 797-800.

11 Owens JJ, Donovan DT, Alford EL (1994) Life-threatening presentations of fibrovascular esophageal and hypopharyngeal polyps. Ann Otol Rhinol Laryngol 103: 838-842. 